\section{Shear capacity of high-strength concrete beams with their point of inflection within the shear span}

\author{
M. S. Islam, BSc(Eng), MEng, MPhil, MIEB, H. J. Pam, ME, PhD, MIEAust, CPEng, \\ and A. K. H. Kwan, BSc(Eng), PhD, CEng, MICE
}

The shear strength of concrete does not increase in proportion with the concrete grade. Thus, when high-strength concrete is used in place of normal-strength concrete, the shear capacity of the structure could become critical. In the study presented, the effect of concrete strength on the shear capacity of concrete beams was investigated. As previous research on normal-strength concrete beams has shown that the presence of an inflection point within the shear span can significantly influence the shear capacity, particular effort was made to study this influence in the case of high-strength concrete beams. The results indicate that, as the concrete strength increases, the shear capacity of the beam also increases, but the shear capacity is proportional to the cube-root rather than the square-root of the concrete compressive strength. It is also revealed that the presence of an inflection point can increase the shear capacity by as much as $100 \%$, regardless of whether normal-strength or high-strength concrete is used. Finally, the test results were analysed by comparing them with the predicted strength values calculated using the formulae given in the various codes and Aoyagi's equation.

Keywords: beams \& girders; concrete structures; strength \& testing of materials

\section{Introduction}

With the rapid advancement of concrete technology, high-strength concrete is becoming increasingly widely used in the construction of high-rise buildings and other reinforcedconcrete structures. However, the tensile and shear strengths of high-strength concrete do not increase in proportion with the compressive strength, and hence they could become more critical. Of the two strength properties, the shear strength is of particular importance because the tensile strength is not normally relied on for carrying loads but shear is unavoidable in beam-column frame structures.

2. Although there has been a rapid growth of interest in high-strength concrete, current specifications for the shear strength of reinforced concrete beams in the American
Concrete Institute (ACI) Building Code, ${ }^{1}$ British Standard $^{2}$ and New Zealand Standard ${ }^{3}$ are based on results of beam tests done using concretes with relatively low compressive strengths. A characteristic of high-strength concrete loaded to failure under compression is that it fractures very suddenly, and in doing so forms failure surfaces that are typically smooth planes. ${ }^{4}$ These smooth failure surfaces contrast greatly with the rough surfaces typical of normalstrength concrete, which comprise irregular cracks that generally follow the aggregatemortar interfaces. It could be expected that the surface of a diagonal shear crack in a highstrength concrete beam would also be relatively smooth and that the smooth surface might be deficient in aggregate interlock (an important component of shear carried by concrete). For this reason, many codes have set the limit that, above a certain compressive strength, no further increase in shear strength should be allowed. The ACI Building Code and New Zealand Standard set this compressive strength level at cylinder strengths of 68.9 and $70.0 \mathrm{MPa}$, respectively. However, the British Standard sets a much lower limit of $40.0 \mathrm{MPa}$ cube strength (equivalent to approximately $30 \mathrm{MPa}$ cylinder strength) above which no further increase in shear strength can be allowed. In view of such a difference, it is considered necessary to check whether the present shear strength prediction equations are reasonable, overly conservative or unsafe when applied to high-strength concrete.

3 . With regard to the way in which the shear strength of concrete increases with the compressive strength, the ACI Building Code ${ }^{1}$ and New Zealand Standard ${ }^{3}$ assume that the nominal shear capacity (the shear capacity of the beam section without shear reinforcement) is essentially a function of the square-root of the compressive strength, while the British

Standard ${ }^{2}$ and some other investigators ${ }^{5,6}$ take it as being proportional to the cube-root of the compressive strength. It is thus apparent that, even for normal-strength concrete, there is no universally accepted relationship between the shear strength and compressive strength. More research on the shear of both normal-strength and high-strength concrete structures is needed.

4. In most of the design codes, the shear
Proc. Instn Civ. Engrs Structs \& Bldgs, 1998, 128 Feb., 91-99

Paper 11509

Written discussion closes 29 May 1998

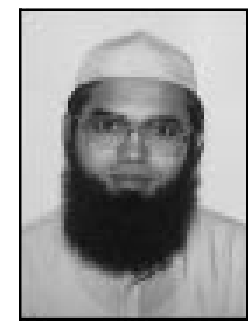

M. S. Islam, Postgraduate Student, Department of Civil and

Structural Engineering, The University of Hong Kong

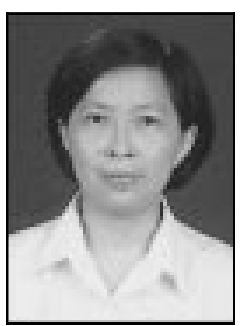

H. J. Pam, Lecturer, Department of Civil and Structural Engineering, The University of Hong Kong

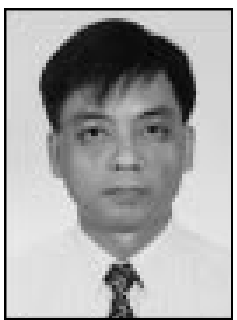

A. K. H. Kwan, Senior Lecturer, Department of Civil and Structural Engineering, The University of Hong Kong 
capacity of a reinforced-concrete member without web reinforcement is calculated by using empirical formulae which are based principally on experimental results obtained using simply supported beams. However, in continuous beams or frame structures, the stress conditions are not quite the same as those in a simply supported beam. The major difference is that, in a continuous beam or a beam that forms part of a frame structure, the bending moment within the shear span can vary from sagging to hogging, or vice versa, as evidenced by the presence of an inflection point within the shear span. In 1993, Aoyagi and Endo $^{7}$ conducted an experimental study on the effect of the presence of an inflection point within the shear span by testing simply supported reinforced concrete beams with overhangs at both ends. The beams were each subjected to a distributed load applied within the two supports, and two point loads applied one each at the end of each overhang. The distributed load induced sagging moments over the central portion of the beam, while the point loads acting on the overhangs induced hogging moments at the supports; therefore, an inflection point was formed within each shear span. Aoyagi and Endo found that the presence of an inflection point within the shear span could increase the shear capacity of the beam by as much as $40 \%$ compared to that of the control beam which was subjected only to distributed load within the two supports. Subsequently, Aoyagi and Islam ${ }^{8,9}$ conducted a similar experiment with the distributed load replaced by two point loads applied symmetrically within the span length (i.e. each beam was subjected to four point loads, two within the span length and one each at the end of each overhang). It was found from the test results that the presence of an inflection point within the shear span could increase the shear capacity by up to $70 \%$ compared to that of the control beam which was subjected to only two point loads within the span. Hence, the effect of the presence of an inflection point within the shear span is even more pronounced in beams subjected to concentrated loads. Both the aforementioned experimental investigations were conducted on normal-strength concrete beams. To the best of the authors' knowledge, no similar study on high-strength concrete beams has ever been conducted.

5. In the present study, an investigation was made of the effects of concrete strength (cube strength of $25-100 \mathrm{MPa}$ ) and the location of the inflection point within the shear span on the shear capacity of a concrete beam. The research programme consisted of testing a total of 25 reinforced-concrete beams under four-point loading and analysis of the test results by comparing them with existing code provisions.

\section{Outline of experiment}

6. Twenty five reinforced-concrete beams of rectangular cross-section having common dimensions of $150 \mathrm{~mm}$ width $\times 250 \mathrm{~mm}$ depth $\times 3400 \mathrm{~mm}$ length were fabricated and tested. All the beams were simply supported at a span of $2200 \mathrm{~mm}$, leaving an overhang of $600 \mathrm{~mm}$ beyond each support. The beams were tested by subjecting each to two point loads symmetrically applied within the span at a constant distance of $800 \mathrm{~mm}$ from the support. In order to simulate the condition prevalent in continuous beams, two point loads, one on each overhanging portion, were also applied to induce hogging moments at the supports. Thus, in effect, the beams were tested under four-point loading (two point loads within the span, and two point loads on the overhanging portions), as shown in Fig. 1.

7. The 25 beams were divided into five groups, each comprising five beams cast of the same concrete and provided with the same reinforcement (i.e. the five beams in the same group were identical). The five groups of beams were cast with concretes of grades $25,40,60,80$ and 100 . Four longitudinal steel bars of the same

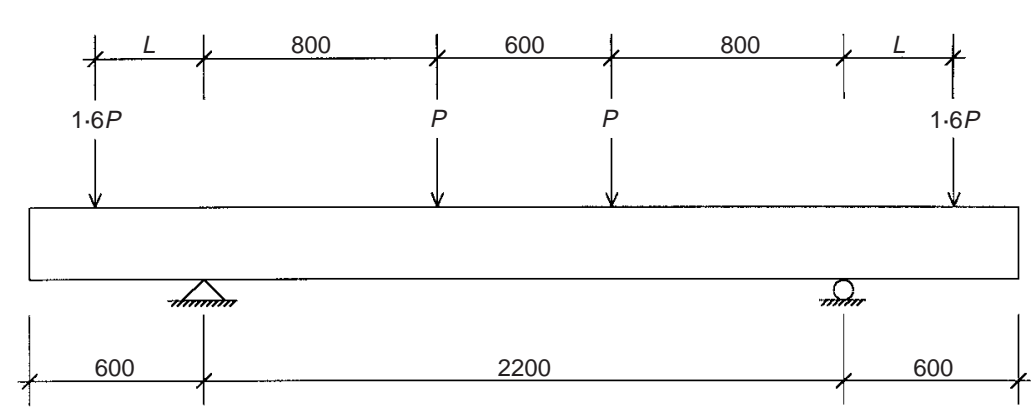

(a)

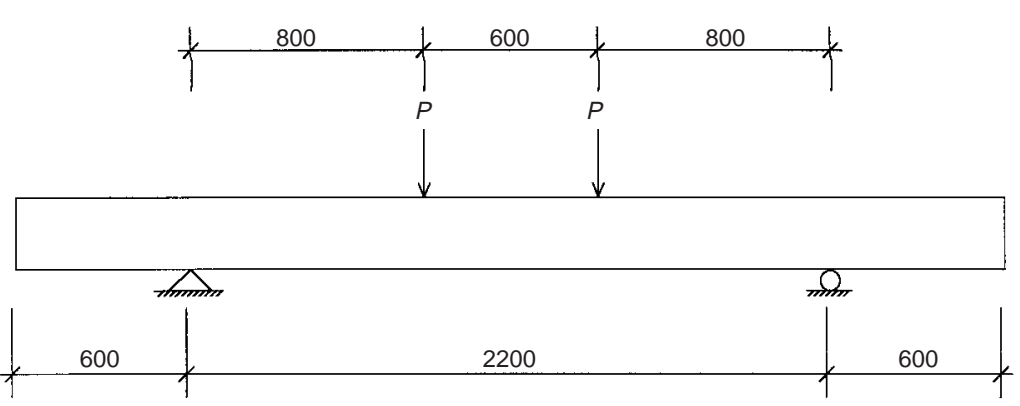

(b)

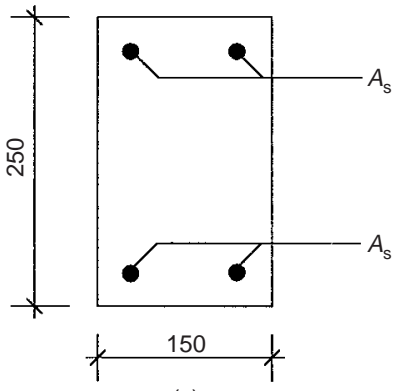

(c)

Fig. 1. Loading arrangement and dimensions ( $m m):(a)$ four-point loading (beams S1-S4); (b) twopoint loading (beam SO); (c) beam section

\section{.}


size were placed in each beam. Two of the longitudinal bars were placed near the top of the beam section and the other two near the bottom (see Fig. 1). Deformed mild steel bars were used in the beams containing normal-strength concrete (grades 25 and 40), whereas deformed high-yield steel bars were used for the remainder of the beams which contained highstrength concrete (grade 60 and higher). The left-hand shear span (the shear span being that part of the beam from the support to the nearest point load applied within the main span) contained no shear reinforcement, but the remaining parts of the beam were provided with more than sufficient shear reinforcement so that any shear failure would be localized within the left-hand shear span. The properties of the materials used and the amount of reinforcement provided in each group of beam specimens are given in Table 1.

8. The five identical beams in each group were designated by beam numbers $\mathrm{S} 0-\mathrm{S} 4$. Beams numbered S1, S2, S3 and S4 were subjected to four-point loading, which induced hogging moments at the supports and sagging moments at the mid span of the beam. Due to the changeover of hogging moments at the supports to sagging moments at the mid span, a point of inflection was formed within each shear span (Fig. 2). As previous research had revealed that the location of the inflection point could significantly influence the shear capacity of the beam, the distance $a_{1}$ of the inflection point from the support was taken as a major parameter to be studied. The location of the inflection point can be controlled either by adjusting the relative magnitudes of the point loads applied at the overhangs to those applied within the main span, or adjusting the positions of the point loads applied on the overhangs. In the present study the magnitude of the point loads applied on the overhangs was controlled at all times to be equal to 1.6 times the magnitude of the two point loads applied within the main span, while the distance $L$ of the point loads applied on the overhangs from the supports was varied to yield different locations of the inflection points. The values of $L$ for the beams S1, S2, S3 and S4 are given in Table 2. The corresponding distances of the inflection point from the support, expressed in non-dimensional form as the ratio $a_{1} / d$, where $d$ is the effective depth of the beam, are also given in Table 2 . The remaining beam, S0, was the control. It was subjected only to two point loads within the main span, and thus the sections at the supports may be taken as inflection points and the value of $a_{1} / d$ as zero. The test results for the control beams were used for comparison purposes to single out the effect of the presence of an inflection point within the shear span. Overall, the testing programme was so designed that the ratio $a_{1} / d$ varied from 0 to 4.
Table 1. Material properties of the beam specimens

\begin{tabular}{|c|c|c|c|c|c|c|}
\hline \multirow{2}{*}{$\begin{array}{l}\text { Beam } \\
\text { group }\end{array}$} & \multicolumn{2}{|c|}{ Concrete strength: $\mathrm{MPa}$} & \multicolumn{3}{|c|}{ Top/bottom reinforcement } & \multirow{2}{*}{$\begin{array}{l}\text { Effective } \\
\text { depth, } d \text { : } \\
\text { mm }\end{array}$} \\
\hline & Cube & Cylinder & $\begin{array}{c}\text { Bar } \\
\text { arrangement* }\end{array}$ & $\begin{array}{c}f_{\mathrm{y}}: \\
\mathrm{MPa}\end{array}$ & $\begin{array}{l}\rho: \\
\%\end{array}$ & \\
\hline M100 & $104 \cdot 2$ & $83 \cdot 3$ & $2 \varnothing 25 \mathrm{~mm}(\mathrm{HS})$ & 532 & $3 \cdot 2$ & 203 \\
\hline M80 & $91 \cdot 3$ & $72 \cdot 2$ & $2 \varnothing 25 \mathrm{~mm}$ (HS) & 532 & $3 \cdot 2$ & 203 \\
\hline M60 & $65 \cdot 4$ & $50 \cdot 8$ & $2 \varnothing 20 \mathrm{~mm}$ (HS) & 554 & $2 \cdot 0$ & 207 \\
\hline M40 & $48 \cdot 2$ & $34 \cdot 4$ & $2 \varnothing 25 \mathrm{~mm}$ (MS) & 320 & $3 \cdot 2$ & 205 \\
\hline M25 & $33 \cdot 9$ & $26 \cdot 6$ & $2 \varnothing 20 \mathrm{~mm}(\mathrm{MS})$ & 350 & $2 \cdot 0$ & 207 \\
\hline
\end{tabular}

* MS, mild steel; HS, high-yield steel.

9. The mix designs of the different grades of concrete used are given in Table 3 . Crushed volcanic rock (maximum size of $10 \mathrm{~mm}$ ) was used as coarse aggregate and crushed volcanic fine passing through a $5-\mathrm{mm}$ sieve was used as fine aggregate. The binders used consisted of ordinary Portland cement (OPC) only for concrete grades 25 and 40, OPC plus pulverized fuel ash (PFA) for concrete grades 60 and 80, and OPC, PFA and condensed silica fume (CSF) for concrete grade 100. A naphthalene-based superplasticizer was added to each concrete mix until a slump of $75 \mathrm{~mm}$ was achieved. Six cubes and three cylinders were cast from each batch of concrete for quality control. Three of the cubes were tested at the age of 7 days, while the other three cubes and the three cylinders were tested

Fig. 2. Diagrams of the bending moment and the point of inflection (dimensions in $\mathrm{mm}$ )

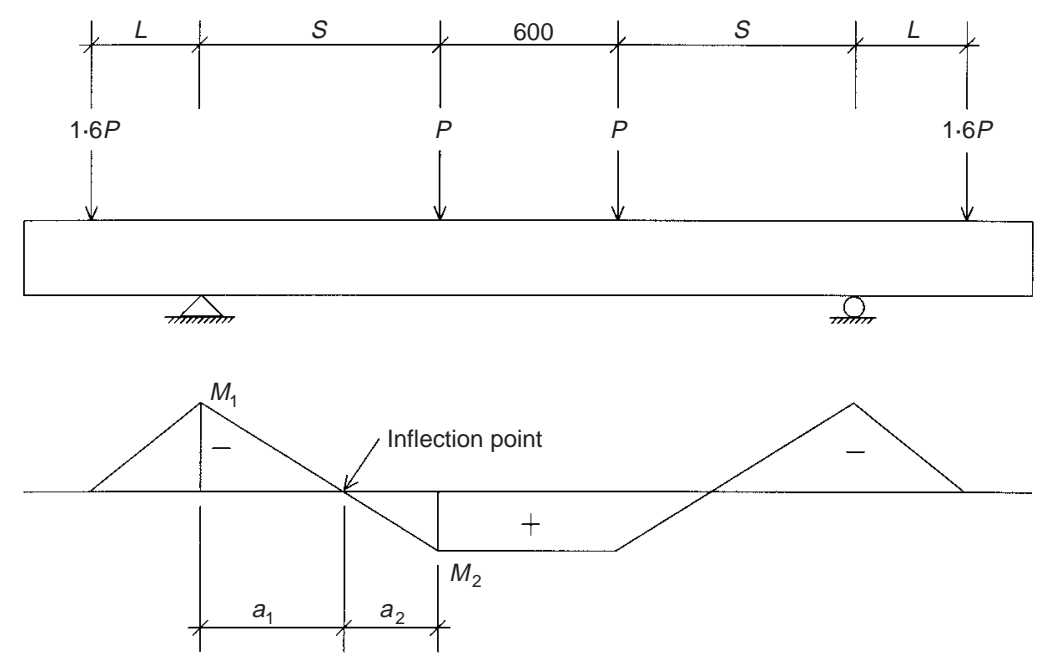

Table 2. Position of the point loads applied on the overhangs and values of the $a_{1} / d$ ratio

\begin{tabular}{l|c|r|r|r|r}
\hline \multirow{2}{*}{} & \multicolumn{5}{|c}{ Beam } \\
\cline { 2 - 6 } & $\mathrm{S} 0$ & $\mathrm{~S} 1$ & $\mathrm{~S} 2$ & $\mathrm{~S} 3$ & $\mathrm{~S} 4$ \\
\hline$L: \mathrm{mm}$ & $-^{*}$ & 125 & 250 & 375 & 500 \\
$a_{1} / d$ & 0 & 1 & 2 & 3 & 4 \\
\hline
\end{tabular}

${ }^{*}$ No load applied on overhanging portion. 
at the age of 28 days. The concrete-strength values given in Table 1 are the mean values of the cubes and cylinders tested at 28 days.

10. The beams were tested using a $1000-\mathrm{kN}$ capacity servo-hydraulic jack controlled by a fully computerized MTS Teststar system (Fig. 3). The load was applied monotonically under load control until the beam failed completely. During the test, vertical deflections were monitored using linear variable displacement transducers at the beam ends, quarter-span points and midspan of the beam. The strains in the longitudinal steel bars at the location where the bending moment was maximum were measured using electrical resistance strain gauges. Visual observations of the cracks were made during the tests. The loads that caused the first flexural crack, the major shear crack and failure of the specimen

\section{Experimental results}

\section{Failure behaviour of the beams}

11. In general, all the beams behaved similarly during the tests, except that they failed at different loads and the crack pattern varied from beam to beam, depending mainly on the location of the inflection point. As the applied load was increased from the preload level (a small load was applied to ensure tight fitting of the loading points before the test started), the vertical deflections and the strains in the steel increased in a more or less linear manner until the beam cracked. The first flexural cracks appeared at the points of maximum moment. For S0 and S1 beams, the maximum moment was sagging and occurred at midspan; for S3 and $\mathrm{S} 4$ beams, the maximum moment was hogging and occurred at the supports; and for S2 beams, the maximum sagging and hogging moments occurred at midspan and the supports, respectively, and were of the same magnitude. As the applied load continued to increase, the flexural cracks gradually increased in number as well as in length, and propagated vertically towards the centroidal axis of the beam (Fig. 4(a)), except for the S2 beams where at a later stage the flexural cracks gradually turned to an inclined direction (Fig. 4(b)).

12. Eventually, the flexural cracks developed into a stable pattern and stopped propagating. Then, suddenly, diagonal shear appeared within the left-hand shear span near the centroidal axis. However, the beams did not fail immediately. In fact, they were able to carry additional loads after the formation of the diagonal shear cracks. As the load was increased further, the diagonal shear cracks propagated simultaneously towards the loading point on the right and the support on the left. As the diagonal crack extended at both ends, the were recorded. cracks inclined at about $45^{\circ}$ to the beam axis

Table 3. Mix proportions of the different grades of concrete

\begin{tabular}{l|c|c|c|c|c}
\hline \multirow{2}{*}{} & \multicolumn{5}{|c}{ Concrete grade: MPa } \\
\cline { 2 - 6 } & 25 & 40 & 60 & 80 & 100 \\
\hline Cement: $\mathrm{kg} / \mathrm{m}^{3}$ & 272 & 308 & 324 & 395 & 400 \\
Water: $\mathrm{kg} / \mathrm{m}^{3}$ & 204 & 185 & 180 & 172 & 170 \\
Fine aggregate: $\mathrm{kg} / \mathrm{m}^{3}$ & 762 & 770 & 751 & 698 & 698 \\
Coarse aggregate: $\mathrm{kg} / \mathrm{m}^{3}$ & 1142 & 1155 & 1127 & 1046 & 1046 \\
Pulverized fuel ash: $\mathrm{kg} / \mathrm{m}^{3}$ & - & - & 36 & 111 & 107 \\
Condensed silica fume: $\mathrm{kg} / \mathrm{m}^{3}$ & - & - & - & - & 26 \\
Superplasticizer: $1 / 100 \mathrm{~kg}$ binder & - & $1 \cdot 3$ & $2 \cdot 2$ & $2 \cdot 2$ & $2 \cdot 2$ \\
\hline
\end{tabular}

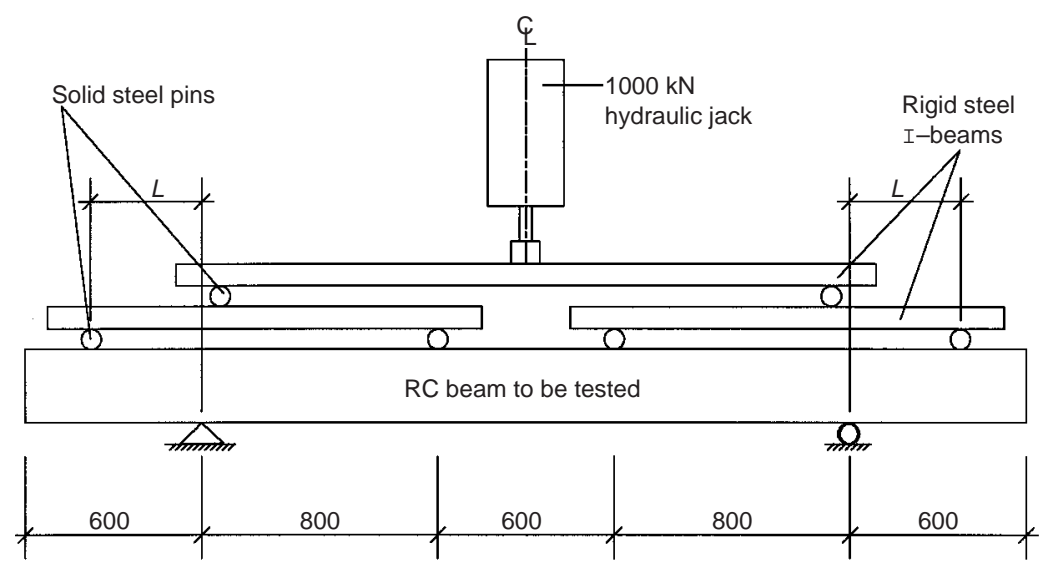

Fig. 3. Application of angle of inclination of the crack extension gradually decreased and, as a result, the shear cracks developed into the shape shown in Fig. 4. Finally, the width of the diagonal shear cracks increased rapidly and the beams failed in shear in a brittle manner. Extensive splitting of the concrete cover along the main steel reinforcement accompanied the shear failure.

13. After the tests had been completed it was noted that the surfaces of the diagonal shear cracks of the high-strength concrete beams
Fig. 4. Typical crack patterns for SO, S1, S3 and $S 4$ beams (a) and S2 beams (b)
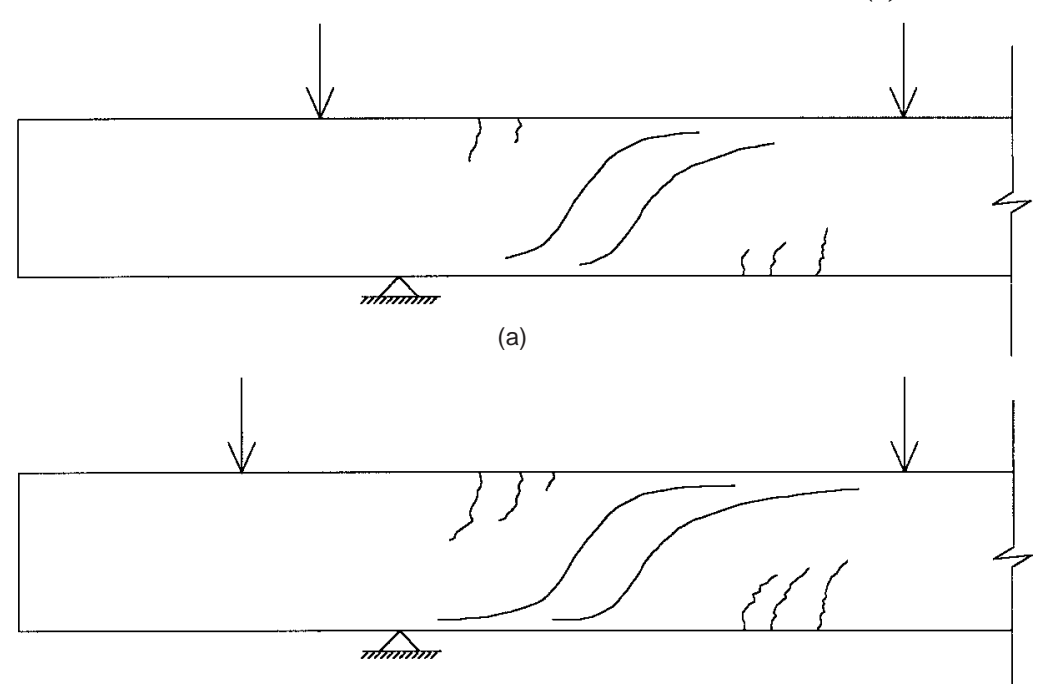

(b) load through a 1000-kN jack. $R C$, reinforced concrete (dimensions in $\mathrm{mm}$ ) 
were distinctly smoother than those of the normal-strength concrete beams. This indicated that the high-strength concrete beams were deficient in aggregate-interlocking action. Throughout the tests, the strain gauge measurements showed that none of the longitudinal reinforcement in any of the beams had yielded.

\section{Effect of concrete strength}

14. The shear strengths of the 25 beams tested are given in Table 4 . It can be seen that both the concrete grade and the location of the inflection point have a significant effect on the shear strength of the concrete beams. In order to isolate the effect of the concrete grade, the mean shear strength of the five beams in each beam group was calculated. The mean values clearly indicate that the shear strength increases with the concrete grade, but the rate of increase in shear strength gradually decreases until the shear strength stops increasing at a concrete grade of 80 . This is probably due to the lower effectiveness of the aggregate interlock in higher strength concrete.

15. It is also noted that the mean shear strength of beam group M60 is lower than that of beam group M40. This is because the amount of longitudinal reinforcement in beam group M60 is smaller. As none of the reinforcement had yielded, the actual yield strength of the steel was of no significance and thus it did not matter whether mild steel or high-yield steel was used as reinforcement. As mild steel and high-yield steel have the same Young's modulus, the only parameter that mattered was the amount of longitudinal reinforcement provided or, to be more precise, the area ratio $\rho$ of the main steel. Two reinforcement-area ratios were used in the study. Beam groups M25 and M60 had the same steel area ratio of $2.0 \%$, and thus their mean shear strengths may be compared directly (Table 5). Likewise, beam groups M40, M80 and M100 had the same steel area ratio $(3 \cdot 2 \%)$ : their mean shear strengths are compared in Table 6 . In Tables 5 and 6 the ratios of the mean shear strength of the beam groups to that of the beam group having the lowest concrete strength are tabulated alongside the square-root and cuberoot of the corresponding ratios of concrete compressive strength. From these results it can be seen that the shear strength ratios are closer to the cube-root rather than the square-root of the concrete compressive strength ratios. Assuming that the shear strength is proportional to the square-root of the concrete strength would tend to overestimate the shear strength of high-strength concrete beams.

16. Overall, it may be concluded that the effect of concrete strength may be best taken into account by assuming that the sectional shear strength varies as the cube-root of the
Table 4. Shear strength of the beams tested

\begin{tabular}{l|c|c|c|c|c|c}
\hline \multirow{2}{*}{$\begin{array}{l}\text { Beam } \\
\text { group }\end{array}$} & \multicolumn{5}{|c}{ Shear strength: MPa } \\
\cline { 2 - 7 } & S0 & S1 & S2 & S3 & S4 & $\begin{array}{c}\text { Mean of } \\
\text { beam group }\end{array}$ \\
\hline M100 & $2 \cdot 14$ & $3 \cdot 55$ & $4 \cdot 32$ & $3 \cdot 19$ & $2 \cdot 66$ & $3 \cdot 17$ \\
M80 & 1.91 & $3 \cdot 86$ & $4 \cdot 05$ & $3 \cdot 80$ & $2 \cdot 37$ & $3 \cdot 20$ \\
M60 & $1 \cdot 47$ & $2 \cdot 97$ & $3 \cdot 34$ & $2 \cdot 91$ & $1 \cdot 67$ & $2 \cdot 47$ \\
M40 & 1.79 & $2 \cdot 76$ & $3 \cdot 13$ & $2 \cdot 63$ & $2 \cdot 51$ & $2 \cdot 56$ \\
M25 & 1.53 & $2 \cdot 17$ & 3.03 & $1 \cdot 82$ & $2 \cdot 11$ & $2 \cdot 13$ \\
\hline
\end{tabular}

Table 5. Comparison of shear strengths of beams with $\rho=2.0 \%$

\begin{tabular}{l|c|c|c|c}
\hline $\begin{array}{c}\text { Beam } \\
\text { group }\end{array}$ & $\begin{array}{c}\text { Ratio of mean } \\
\text { shear strength to } \\
\text { that of M25 beams }\end{array}$ & $\begin{array}{c}\text { Ratio of mean } \\
\text { cube strength to } \\
\text { that of M25 beams }\end{array}$ & $\begin{array}{c}\text { Square-root of } \\
\text { cube strength } \\
\text { ratio }\end{array}$ & $\begin{array}{c}\text { Cube-root of } \\
\text { cube strength } \\
\text { ratio }\end{array}$ \\
\hline M60 & 1.16 & 1.93 & 1.39 & 1.25 \\
M25 & 1.00 & 1.00 & 1.00 & 1.00 \\
\hline
\end{tabular}

Table 6. Comparison of shear strengths of beams with $\rho=3 \cdot 2 \%$

\begin{tabular}{l|c|c|c|c}
\hline $\begin{array}{l}\text { Beam } \\
\text { group }\end{array}$ & $\begin{array}{c}\text { Ratio of mean } \\
\text { shear strength to } \\
\text { that of M40 beams }\end{array}$ & $\begin{array}{c}\text { Ratio of mean } \\
\text { cube strength to } \\
\text { that of M40 beams }\end{array}$ & $\begin{array}{c}\text { Square-root of } \\
\text { cube strength } \\
\text { ratio }\end{array}$ & $\begin{array}{c}\text { Cube-root of } \\
\text { cube strength } \\
\text { ratio }\end{array}$ \\
\hline M100 & 1.24 & 2.16 & 1.47 & 1.29 \\
M80 & 1.25 & 1.89 & 1.37 & 1.24 \\
M40 & 1.00 & 1.00 & 1.00 & 1.00 \\
\hline
\end{tabular}

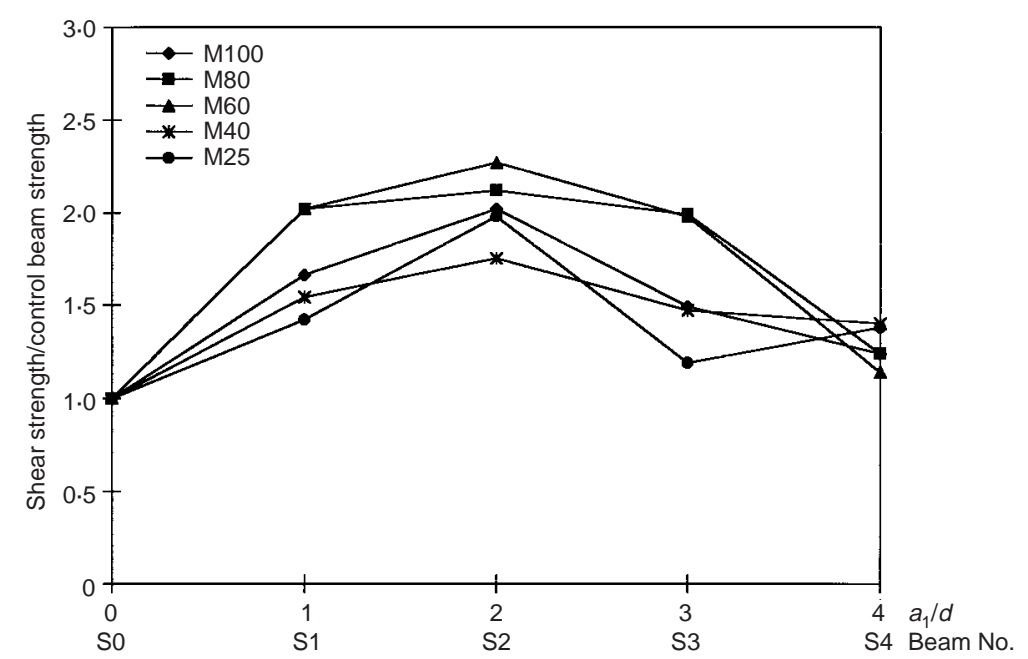

Fig. 5. Effect of inflection point on shear strength

Table 7. Values of $\mathrm{a}_{1}, \mathrm{a}_{2}$, a and $\mathrm{a} / \mathrm{d}$

\begin{tabular}{l|r|r|r|r|r}
\hline \multirow{2}{*}{} & \multicolumn{5}{|c}{ Beam number } \\
\cline { 2 - 6 } & $\mathrm{S} 0$ & $\mathrm{~S} 1$ & $\mathrm{~S} 2$ & $\mathrm{~S} 3$ & $\mathrm{~S} 4$ \\
\hline$a_{1}: \mathrm{mm}$ & 0 & 200 & 400 & 600 & 800 \\
$a_{2}: \mathrm{mm}$ & 800 & 600 & 400 & 200 & 0 \\
$a: \mathrm{mm}$ & 800 & 600 & 400 & 600 & 800 \\
$a / d$ & 4 & 3 & 2 & 3 & 4 \\
\hline
\end{tabular}


concrete strength up to a concrete grade of 80 , beyond which no further increase in shear strength should be allowed. There is still an increase in shear strength of about $25 \%$ when the concrete grade is raised from 40 to 80 , and thus it would be overly conservative if no further increase in shear strength beyond a concrete grade of 40 is allowed.

Influence of the location of the inflection point

17. In order to visualize the effect of the inflection point, the ratios of the sectional shear capacities of the $\mathrm{S} 1, \mathrm{~S} 2, \mathrm{~S} 3$ and $\mathrm{S} 4$ beams to that of the control beam ( $\mathrm{S} 0)$ are plotted against the corresponding values of the ratio $a_{1} / d$ in Fig. 5 . It is seen that the presence of an inflection point within the shear span can increase the shear capacity of a beam by as much as $100 \%$. The maximum increase in shear capacity occurs when $a_{1} / d=2$; that is, when the inflection point is at the middle of the shear span. The general trend in the variation of the shear capacity with the $a_{1} / d$ ratio is similar in the different beam

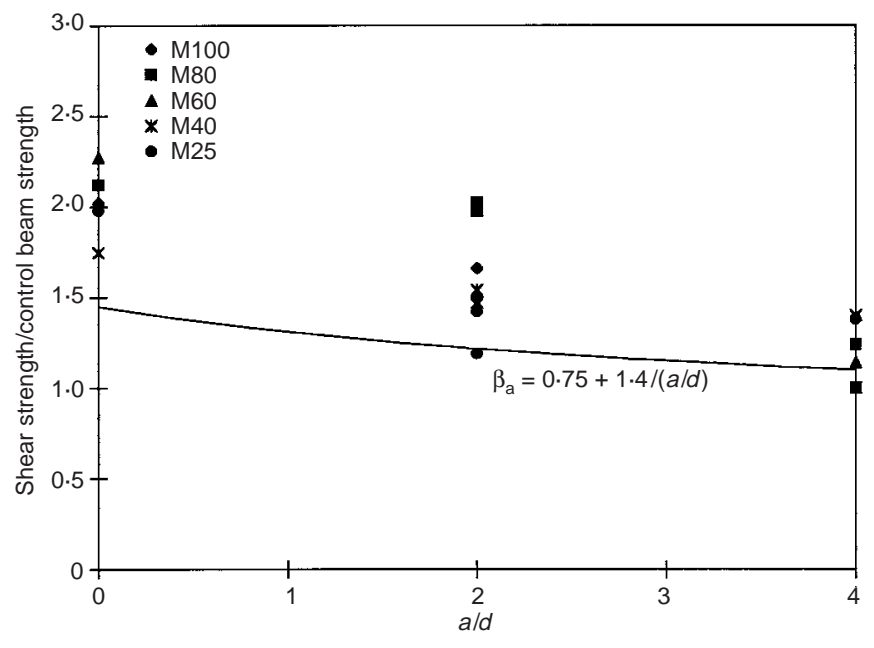

groups of different concrete strengths. Thus the effect of the inflection point in high-strength Fig. 6. Variation of shear strength with the $\mathrm{a} / \mathrm{d}$ ratio

Table 8. Comparison of the test results with existing code provisions and Aoyagi's equation

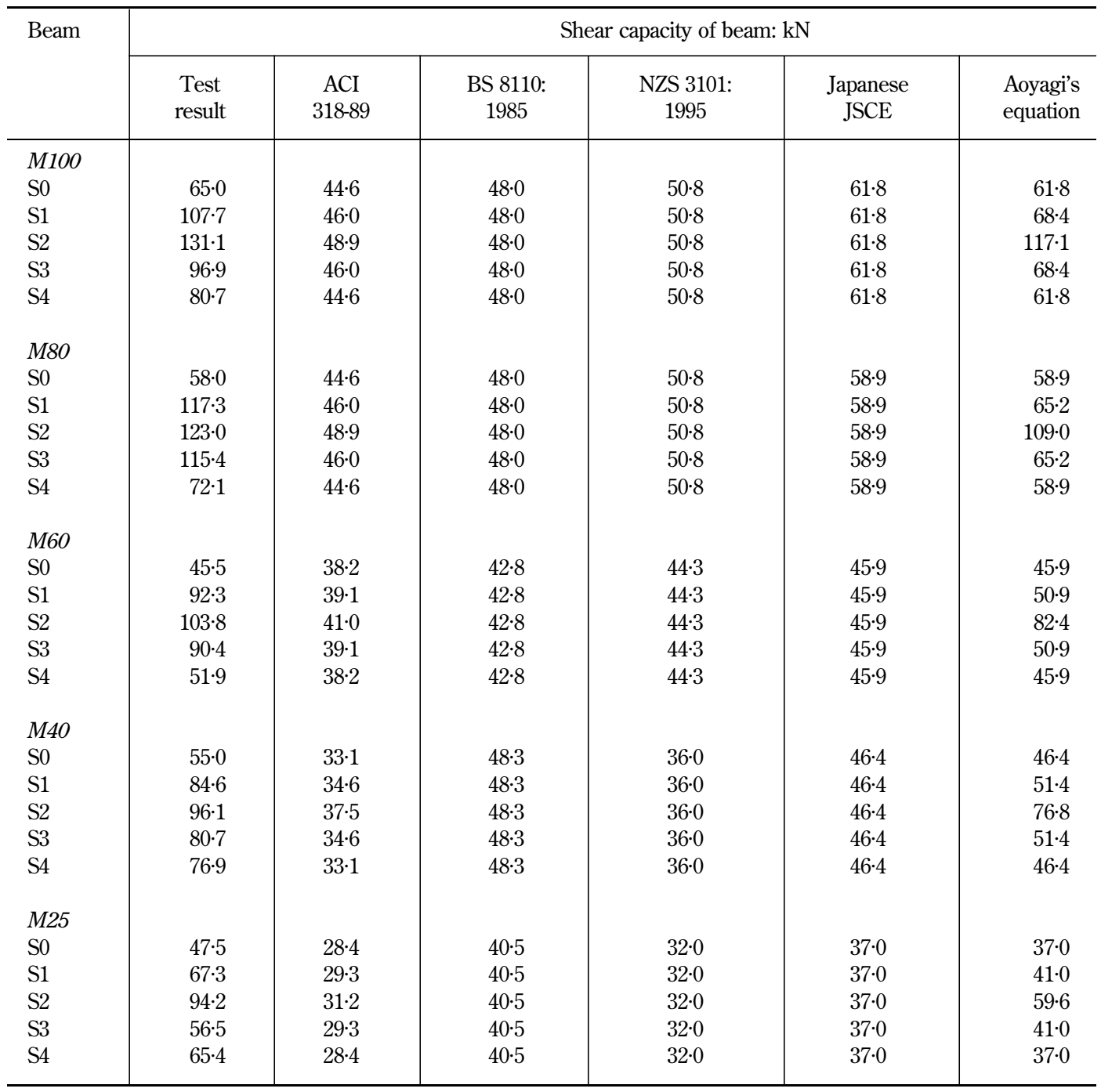


18. As suggested by Aoyagi and Endo, ${ }^{7}$ the effect of the inflection point may be explained by considering a fictitious support at the inflection point that divides the shear span into two shorter shear spans, one of length $a_{1}$ and the other of length $a_{2}$ (see Fig. 2). Hence, the length of the shear span is reduced from $S$ to either $a_{1}$ or $a_{2}$, and since a beam with shorter shear span can generally resist higher shear load, the shear capacity is increased. As the longer shear span has lower shear strength, it is the larger of $a_{1}$ or $a_{2}$ that determines the shear capacity of the beam. Denoting the larger value of $a_{1}$ and $a_{2}$ by $a$, it is postulated that the effect of the inflection point is mainly a function of $a / d$, and that the sectional shear capacity of the beam varies with $a / d$ as in the case of a deep beam or a beam with very short shear span. The values of $a_{1}, a_{2}, a$ and $a / d$ for the beams tested are listed in Table 7 , from which it can be seen that the beam S2 has the smallest value of $a / d$. This is why the S2 beams have the highest shear capacities within the beam groups.

19. In order to study how the sectional shear capacity varies with the $a / d$ ratio, Fig. 5 was replotted with the quantity on the abscissa being $a / d$, rather than $a_{1} / d$ (Fig. 6). The results show very clearly that the section shear capacity decreases as $a / d$ increases, or vice versa. Aoyagi and Endo have proposed the use of the following factor, which is being used in the Japanese JSCE Code ${ }^{10}$ to allow for the effect of the shear span, for estimating the effect of the inflection point:

$$
\beta_{\mathrm{a}}=0 \cdot 75+\frac{1 \cdot 4}{a / d}
$$

This factor is also plotted in Fig. 6 for comparison with the test results. The comparison reveals that the above equation is generally a reasonably accurate and conservative estimate of the effect of the inflection point.

\section{Comparison with existing code provisions and Aoyagi's equation}

20. In Table 8 the test results are compared with the predicted strengths calculated using the corresponding equations given in the ACI Building Code, ${ }^{1}$ British Standard, ${ }^{2}$ New Zealand Standard, ${ }^{3}$ Japanese JSCE Code ${ }^{10}$ and Aoyagi's equation. ${ }^{7}$ The equations used in the calculations are given in the Appendix. In order to visualize the comparison better, the test results and the predicted strength values of the M40 and M100 beams are plotted in Figs 7 and 8, respectively.

21. The comparison in Table 8 shows that for the control beams ( $\mathrm{S} 0$ ) and the beams designated S4 the existing codes predict reasonably well the shear capacities of the beams and are basically on the safe side. The ACI Building

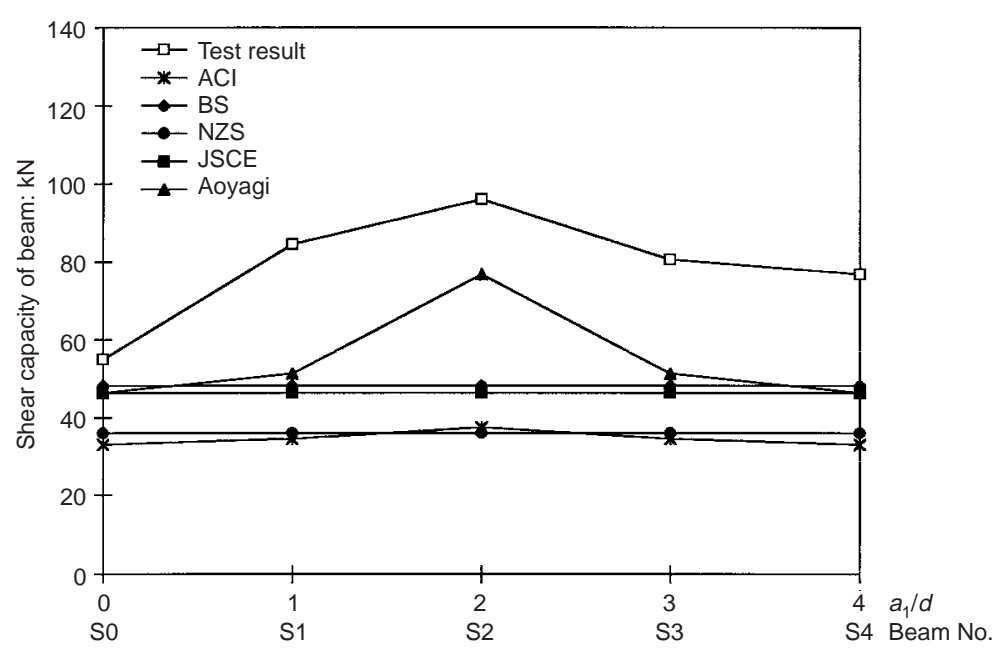

Fig. 7. Test results and predicted strength values for the M40 beams

Code is consistently the most conservative of the codes studied. On the other hand, the British Standard yields the highest shear strength values when applied to normalstrength concrete but becomes relatively conservative when applied to high-strength concrete because it does not allow for an increase in shear strength above a concrete grade of 40 .

22. The comparisons in Table 8 and in Figs 7 and 8 show that for the beams designated S1, S2 and S3, which have substantially higher shear strength than the control beams in the same beam group, all the existing codes significantly underestimate their shear strength. This is because the effect of the inflection point has not been properly allowed for in these codes. However, Aoyagi's equation, which is modified from the Japanese JSCE Code to allow for the effect of the inflection point (equation (1)), yields predicted shear strength values that are in closest agreement with the test results, and still remain generally on the safe side.

Fig. 8. Test results and predicted strength values for the M100 beams

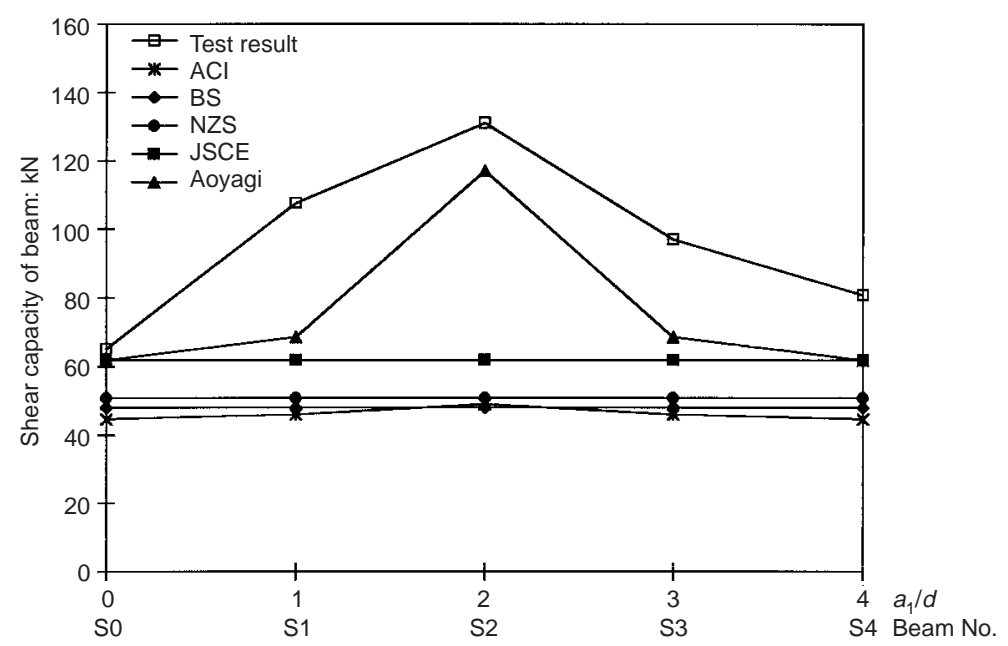




\section{Conclusions}

23. A number of beams cast of normalstrength and high-strength concretes were tested under four-point loading to study the effects of the concrete strength and the inflection points within the shear spans on the shear strength of the beams. The test results and their comparison with the existing code provisions and Aoyagi's equation revealed the following.

(a) The shear strength of a reinforced-concrete beam without stirrups increases with increasing concrete compressive strength, but the rate of increase in shear strength gradually decreases as the concrete strength increases until the shear strength stops increasing at a concrete cube strength of about $80 \mathrm{MPa}$. Below this concrete strength level the shear strength of a concrete beam varies more or less as a cuberoot function of the concrete compressive strength.

(b) The presence of an inflection point within the shear span can increase the shear capacity of the concrete beam by as much as $100 \%$, regardless of whether the beam is cast of normal-strength or high-strength concrete. Generally speaking, the effect of the inflection point in high-strength concrete is similar to that in normal-strength concrete. As suggested by Aoyagi and Endo, the effect of the inflection point may be allowed for by assuming that there is a fictitious support at the inflection point that divides the shear span into two shorter shear spans. It is this shortening of the shear span that leads to the increase in shear strength. The factor given in equation (1) may be used to estimate the effect of the inflection point in both normal-strength and high-strength concretes.

(c) For beams with no inflection points within their shear span the existing codes predict the shear capacities of the beams reasonably well. However, for beams with inflection points within their shear span, the existing codes significantly underestimate the shear strength of the beams because the effect of the inflection points has not been properly allowed for in these codes.

(d) Aoyagi's equation, which is modified from that used in the Japanese JSCE Code by changing the value of the shear span length $a$ to the larger of $a_{1}$ and $a_{2}$, as defined in Fig. 2, predicts fairly accurately the shear strength of all the beams tested, including those cast of high-strength concrete.

Hence, Aoyagi's equation is also applicable to high-strength concrete beams.

\section{Acknowledgement}

Grants Council of Hong Kong for the research work presented herein is gratefully acknowledged.

\section{Appendix}

ACI Building Code ACI 318-89 ${ }^{1}$

$$
V_{\mathrm{c}}=\left(0 \cdot 16 \sqrt{ } f_{\mathrm{c}}+17 \cdot 2 \rho_{\mathrm{w}} \frac{V_{\mathrm{u}} d}{M_{\mathrm{u}}}\right) b_{\mathrm{w}} d
$$

where $V_{\mathrm{c}}$ is the nominal shear strength of the section provided by the concrete $(\mathrm{N}), f_{\mathrm{c}}$ is the compressive cylinder strength of the concrete $(\mathrm{MPa}), \rho_{\mathrm{w}}$ is the area ratio of tension reinforcement, $V_{\mathrm{u}}$ is the factored shear force at the section $(\mathrm{N}), M_{\mathrm{u}}$ is the factored moment occurring simultaneously with $V_{\mathrm{u}}(\mathrm{N} \mathrm{mm}), b_{\mathrm{w}}$ is the web width of the beam ( $\mathrm{mm})$ and $d$ is the effective depth of the beam (mm).

25. Note: $f_{\mathrm{c}}$ should not be taken as greater than $68.9 \mathrm{MPa} ; V_{\mathrm{u}} d / M_{\mathrm{u}}$ should not be taken as greater than 1 .

$$
\begin{aligned}
& \text { British Standard BS } 8110^{2} \\
& \qquad V_{\mathrm{c}}=\left[0 \cdot 79\left(100 \frac{A_{\mathrm{s}}}{b_{\mathrm{v}} d}\right)^{\frac{1}{3}}\left(\frac{400}{d}\right)^{\frac{1}{4}}\left(\frac{f_{\mathrm{cu}}}{25}\right)^{\frac{1}{3}}\right] b_{\mathrm{v}} d
\end{aligned}
$$

where $V_{\mathrm{c}}$ is the shear strength of the section $(\mathrm{N}), f_{\mathrm{cu}}$ is the compressive cube strength of concrete $(\mathrm{MPa}), A_{\mathrm{s}}$ is the area of tension reinforcement, $b_{\mathrm{v}}$ is the width of the beam $(\mathrm{mm})$ and $d$ is the effective depth of the beam (mm).

26. Note: $f_{\text {cu }}$ should not be taken as greater than $40 \mathrm{MPa} ; 100 A_{\mathrm{s}} /\left(b_{\mathrm{v}} d\right)$ should not be taken as greater than $3 ; 400 / d$ should not be taken as less than 1.

\section{New Zealand Standard NZS $3101^{3}$}

$$
V_{\mathrm{c}}=\left[\left(0.07+10 \rho_{\mathrm{w}}\right) \sqrt{ } f_{\mathrm{c}}\right] b_{\mathrm{w}} d
$$

where $V_{\mathrm{c}}$ is the shear strength of the section $(\mathrm{N}), f_{\mathrm{c}}$ is the compressive cylinder strength of the concrete $(\mathrm{MPa}), \rho_{\mathrm{w}}$ is the area ratio of tension reinforcement, $b_{\mathrm{w}}$ is the web width of the beam $(\mathrm{mm})$ and $d$ is the effective depth of the beam $(\mathrm{mm})$.

27. Note: $f_{\mathrm{c}}$ should not be taken as greater than $70 \mathrm{MPa} ; 0 \cdot 07+10 \rho_{\mathrm{w}}$ should not be taken as greater than 0.20 or less than 0.08 .

$$
\begin{aligned}
& \text { Japanese JSCE Code } 10 \\
& 28 \text {. For a shallow beam }(a / d \geqslant 2) \text { : } \\
& V_{\mathrm{c}}=0.9 \beta_{\mathrm{d}} \beta_{\mathrm{p}} \beta_{\mathrm{a}} f_{\mathrm{cd}}^{\frac{1}{3}} b_{\mathrm{w}} d
\end{aligned}
$$

where $V_{\mathrm{c}}$ is the shear strength of the section (kgf), $\beta_{\mathrm{d}}=(100 / d)^{\frac{1}{4}}$ (if $\beta_{\mathrm{d}}>1 \cdot 5$, then $\left.\beta_{\mathrm{d}}=1 \cdot 5\right), \beta_{\mathrm{p}}$ $=\left(100 \rho_{\mathrm{w}}\right)^{\frac{1}{3}}$ (if $\beta_{\mathrm{p}}>1.5$, then $\left.\beta_{\mathrm{p}}=1.5\right), \beta_{\mathrm{a}}=0.75$ $+[1 \cdot 4 /(a / d)]$ (where $a$ is the shear span length (cm), $f_{\mathrm{cd}}$ is the compressive cylinder strength of concrete $\left(\mathrm{kgf} \mathrm{cm}^{-2}\right), d$ is the effective depth of the beam $(\mathrm{cm}), b_{\mathrm{w}}$ is the web width of the 
beam $(\mathrm{cm})$ and $\rho_{\mathrm{w}}$ is the area ratio of tension reinforcement.

29. Note: The shear span length is taken as the distance from the support to the nearest concentrated load. In other words, in the evaluation of the value of $a$, the presence of the inflection point is ignored.

30. For a deep beam $(a / d<2)$ :

$$
V_{\mathrm{c}}=0.6 \beta_{\mathrm{d}} \beta_{\mathrm{p}} \beta_{\mathrm{a}} f_{\mathrm{cd}}^{\frac{1}{2}} b_{\mathrm{w}} d
$$

where $\beta_{\mathrm{a}}=5 /\left[1+(a / d)^{2}\right]$, and all other parameters are the same as in equation (5).

\section{Aoyagi's equation ${ }^{7}$}

31. This is the same as the equations given in the JSCE Code (equations (5) and (6) for shallow and deep beams, respectively), except that the value of $a$ is taken as the larger value of $a_{1}$ and $a_{2}$ (i.e. the presence of the inflection point is allowed for).

\section{References}

1. American Concrete Institute. Building Code Requirements for Reinforced Concrete (ACI 318-89) and Commentary (ACI 318R-89) (Revised 1992), American Concrete Institute, Detroit, 1992, revised.

2. British Standards Institution. Structural Use of Concrete. BSI, Milton Keynes, 1985, BS8110: Part 1.
3. New Zealand Standards. The Design of Concrete Structures. New Zealand Standards, Wellington, 1995, NZS 3101: Part 1.

4. Carrasquillo R. L., Nilson A. H. and Slate F. O. Properties of high-strength concrete subject to short-term loads. ACI Journal, 1981, 78, No. 3, 171-178.

5. Ahmad S. H., Khaloo A. R. and Poveda A. Shear capacity of reinforced high-strength concrete beams. ACI Journal, 1986, 83, No. 2, 297-305.

6. Zsutry T. C. Beam shear strength prediction by analysis of existing data. ACI Journal, 1968, 65, No. 11, 943-951.

7. Aoyagi Y. and Endo T. Ultimate shear capacity of continuous RC beams subjected to distributed loading. Proceedings, Fourth East Asia-Pacific Conference on Structural Engineering and Construction, Seoul, 1993, pp. 727-732.

8. Aoyagi Y., Taweer C. and Islam M. S. Effects of the position of inflection points on the ultimate shear capacity of reinforced concrete beams.

Transactions of the Japan Concrete Institute, 1994, 16, No. 2, 593-598.

9. IsLam M. S. Effects of the Position of Inflection Points on the Ultimate Shear Capacity of Reinforced Concrete Beams. AIT Thesis No. ST-93-12, Asian Institute of Technology, Bangkok, Thailand, 1993.

10. Japan Society of Civil Engineers. Specification for Design and Construction of Concrete Structures: Design, Japan Society of Civil Engineers, Tokyo, 1986, JSCE Standard, Part 1. 